\title{
Prevalence of Overweight and Obesity And its Correlates in Medical And Nursing Students of UPUMS, Saifai, Etawah
}

\author{
Anamika Singh ${ }^{1}$, Nupur Gupta ${ }^{2}$, NP Singh ${ }^{3}$, PK Jain ${ }^{4}$, Peeyush Kariwala ${ }^{5}$, \\ Vidya Rani ${ }^{6}$ \\ ${ }^{I}$ Dept. Of Physiology, UPUMS, Saifai, Etawah, India \\ 2,3,4,5,6 Dept. Of Community Medicine, UPUMS, Saifai, Etawah, India
}

Corresponding Author: Dr NP Singh, ${ }^{3}$ Associate Professor, nareshpalsingh@gmail.com

\begin{abstract}
Introduction: Obesity is the most common expression of unhealthy diet often combined with lack of physical activity. We are amidst an epidemic of obesity which has serious health ramifications. Easy availability of fast foods, junk food culture and sedentary life style add fuel to fire. Realizing this fact, the present study was undertaken on medical and nursing students.

Aim: To study the prevalence and correlates of overweight and obesity in medical and nursing students. Objectives: 1-To study the prevalence of overweight and obesity in medical and nursing students of various batches. 2- To study the correlates of overweight and obesity medical and nursing students. Methods: It was a cross sectional observational study. The study population consists of 519 medical and nursing students of UPUMS Saifai, Etawah. A predesigned and pretested questionnaire was used for data collection. General information and anthropometric measurements of the subjects were done for BMI, waist circumference and waist-hip ratio.

Observations: The study population comprised of 338 medical students (201 males, 137 females) and 181 nursing students (77 males, 104 females). According to BMI, 22.8\% of the medical students were overweight (BMI 25.0-29.9 kg/m ${ }^{2}$ ) and $1.48 \%$ were obese $\left(B M I \geq 30 \mathrm{~kg} / \mathrm{m}^{2}\right)$. On the other hand, $16.0 \%$ of the nursing students were underweight having BMI<normal and $16.6 \%$ had overweight while $2.2 \%$ were obese. Considering waist circumference, $1.49 \%$ of male medical students and $8.76 \%$ of female medical students were obese. While in nursing students, no males were obese and 0.97\% females were obese. Considering waist hip ratio, only $2 \%$ of male medical students and $31.4 \%$ of the females had waist hip ratio higher than normal. While in nursing students, the entire male had normal waist hip ratio and $17.5 \%$ nursing female students had waist hip ratio more than 0.85 .
\end{abstract}

Conclusion: Medical \& nursing students have higher deposition of fat making them more vulnerable to comorbidities of overweight and obesity.

Keywords: Body mass index, Medical students, Obesity, Overweight, Waist-hip ratio

\section{Introduction}

Obesity is the most common expression of unhealthy diet often combined with lack of physical activity. We are amidst an epidemic of obesity which has serious health ramifications. Overweight and obesity are now so common with in the world's population that it is beginning to replace under-nutrition and infectious disease as the most significant contributor to ill health.

Worldwide, obesity has more than doubled since 1980. In 2014, more than 1.9 billion adults [18 years and older], were over-weight. Of these, over 600 million were obese. In 2014, 39\% of adults [aged 18 years and over] (38\% of men and $40 \%$ of women) were overweight and $13 \%$ (11\% of men and $15 \%$ of women) were obese [1]. Childhood obesity is a fast emerging problem. Effective prevention of adult obesity will require prevention and management of childhood obesity.

It is a fast growing problem in the developing countries like India too and is now known to be associated with increased health risk. Obesity is a risk factor in the development of hypertension, diabetes, gall bladder disease and coronary heart diseases and certain types of cancers .Other co-morbid conditions associated with obesity are varicose vein, abdominal hernia, osteoarthritis of weight bearing joints and psychological stress.

Prevalence of obesity varies with in the country because of difference in lifestyle, mainly in the dietary patterns and physical activity. In addition to this, urbanization and industrialization is the main culprit for increase in prevalence of obesity. There is convincing evidence that increase in the energy density of the diet by fat or sugar together with concomitant eating behaviors like snacking, junk food, binge eating and eating out promote unhealthy weight gain through passive over consumption of energy. Consequent upon the economic 
development and market globalization, traditional energy dilute foods are being replaced by widely advertised highly processed energy dense foods. Therefore, there is an imperative need for restriction of consumption of energy dense foods in order to check further progress of the epidemic. WHO has also emphasized on the urgent need of understanding the prevalence trend, factors contributing and developing strategies for effective intervention.

With this background in event, present study was undertaken in medical and nursing students of UPUMS institute to get the prevalence of overweight and obesity with the help of three parameters BMI, waist hip ratio (WHR) and waist circumference (WC).

\section{Aim}

To study the prevalence of overweight and obesity in medical and nursing students at UPUMS, Etawah.

\section{Objectives}

To study the prevalence of overweight and obesity in medical students with respect to BMI, WHR and WC

To study the prevalence of overweight and obesity in nursing students according to three parametres

To study the correlates of overweight and obesity in medical and nursing students

\section{Materials And Methods}

We had conducted a cross sectional study and the study population comprised all the medical students and B.Sc. Nursing students at UPUMS (338 medical students and 181 nursing students), who had given consent and were available for data collection from June 2016 to July 2016. A predesigned and pretested questionnaire was used for data collection. General information regarding age, sex, type of family, socioeconomic status, education and occupation of parents was collected. Information regarding their dietary habits, lifestyle and body weight perceptions was collected.

Height and weight of each individual was measured with the help of stadiometer and weighing machine respectively. Body mass index was used parameter to classify overweight and obesity. It is defined as the weight in $\mathrm{kg}$ divided by square of his height in metres $\left(\mathrm{kg} / \mathrm{m}^{2}\right)$. According to WHO classification (2000) cut off values were used to classify overweight and obesity in students [2]. BMI values are age independent and same for both sexes.

Waist circumference and hip circumference was measured using fibre plastic tape. Waist circumference was measured at the midpoint between lower border of rib cage and iliac crest while hip circumference was measured at the level of greater trochanter. Waist circumference (WC) and waist to hip ratio (WHR) was calculated which are the approx indices of the intra abdominal fat mass and total body fat and there is increased risk of metabolic complications for those men with a waist circumference of $\geq 102 \mathrm{~cm}$ and women with waist circumference of $\geq 88 \mathrm{~cm}[3]$. High waist to hip ratio $>1$ in men and $>0.85$ in women indicates abdominal fat accumulation. The data thus collected was entered in excel sheet and analyzed using SPSS 23 version.

\section{Results And Discussion}

The study population comprised of 338 medical students [males: 201(59.47 \%), females: 137 (40.53\%)] and 181 nursing students [males: 78 (43.09\%), females: 103(56.91\%)].

Table 1: Prevalence of overweight and obesity in medical and nursing students according to various indices

\begin{tabular}{|c|c|c|c|c|c|c|}
\hline \multirow[b]{2}{*}{ Indices } & \multicolumn{3}{|c|}{ Medical students $\quad(n=338)$} & \multicolumn{3}{|c|}{ Nursing students $(\mathrm{n}=181)$} \\
\hline & $\begin{array}{c}\text { Male } \\
(n=201)\end{array}$ & $\begin{array}{l}\text { Female } \\
(n=137)\end{array}$ & $\begin{array}{c}\text { Total } \\
(\mathbf{n}=338)\end{array}$ & $\begin{array}{c}\text { Male } \\
(n=78)\end{array}$ & $\begin{array}{l}\text { Female } \\
(n=103)\end{array}$ & $\begin{array}{c}\text { Total } \\
(\mathbf{n}=181)\end{array}$ \\
\hline \multicolumn{7}{|c|}{ BODY MASS INDEX $\left(\mathrm{Kg} / \mathrm{m}^{2}\right)$} \\
\hline$<18.5$ & $6(3 \%)$ & $24(17.5 \%)$ & $30(8.8 \%)$ & $7(9 \%)$ & $22(21.4 \%)$ & $29(16.02 \%)$ \\
\hline 18.5 - 24.9 & $137(68.2 \%)$ & $89(65 \%)$ & $226(66.86 \%)$ & $54(69.2 \%)$ & $64(62.1 \%)$ & $118(65.19 \%)$ \\
\hline $25.0-29.9$ & $55(27.4 \%)$ & $22(16 \%)$ & $77(22.8 \%)$ & $15(19.2 \%)$ & $15(14.6 \%)$ & $30(16.57 \%)$ \\
\hline 30.0 - 34.9 & $2(1 \%)$ & $1(0.7 \%)$ & $3(0.89 \%)$ & $2(2.6 \%)$ & $2(1.9 \%)$ & $4(2.21 \%)$ \\
\hline 35.0 - 39.9 & $1(0.5 \%)$ & $1(0.7 \%)$ & $2(0.59 \%)$ & $0(0 \%)$ & $0(0 \%)$ & $0(0 \%)$ \\
\hline$\square \mathbf{4 0 . 0}$ & $0(0 \%)$ & $0(0 \%)$ & $0(0 \%)$ & $0(0 \%)$ & $0(0 \%)$ & $0(0 \%)$ \\
\hline \multicolumn{7}{|c|}{$\begin{array}{llll}\text { BMI vs. Gender in Medical Students } & ?^{2}=24.2 & \text { df }=4 & p<0.001 \\
\text { BMI: Medical vs Nursing students } & ?^{2}=\mathbf{1 0 . 1} & \text { df }=4 & \mathbf{p}=0.038\end{array}$} \\
\hline \multicolumn{7}{|c|}{ WAIST CIRCUMFERENCE (cms) } \\
\hline $\begin{array}{r}\mathbf{(} \square \mathbf{1 0 2} \text { in } \\
\text { Males \& } \\
\square 88 \text { in } \\
\text { females) }\end{array}$ & $3(1.49 \%)$ & $12(8.76 \%)$ & $15(4.44 \%)$ & $0(0 \%)$ & $1(0.97 \%)$ & $1(0.55 \%)$ \\
\hline $\begin{array}{r}(<102 \text { in males } \\
\& \\
<88 \text { in } \\
\text { females })\end{array}$ & $198(98.51 \%)$ & $125(91.24 \%)$ & $323(95.56 \%)$ & $78(100 \%)$ & $102(99.03 \%)$ & $180(99.45 \%)$ \\
\hline
\end{tabular}


Prevalence Of Overweight And Obesity And Its Correlates In Medical And Nursing Students Of..

\begin{tabular}{|c|c|c|c|c|c|c|}
\hline \multicolumn{3}{|c|}{ Waist Circumference vs Gender in Medical Students } & $?^{2}=10.1$ & \multicolumn{3}{|c|}{$\mathrm{p}=\mathbf{0 . 0 0 1}$} \\
\hline \multicolumn{7}{|c|}{ WAIST HIP RATIO (WHR) } \\
\hline $\begin{array}{r}>1 \text { in males \& } \\
>0.85 \text { in } \\
\text { females })\end{array}$ & $4(1.99 \%)$ & $43(31.39 \%)$ & $47(13.9 \%)$ & $0(0 \%)$ & $18(17.48 \%)$ & $18(9.94 \%)$ \\
\hline $\begin{array}{r}\text { ( } \square \text { in males } \\
\& \\
\square \mathbf{0 . 8 5} \text { in } \\
\text { females) }\end{array}$ & 197(98\%) & $94(68.61 \%)$ & $291(86.09 \%)$ & $78(100 \%)$ & $85(82.52 \%)$ & $163(90.05 \%)$ \\
\hline Waist hip ratio $v$ & der in $\mathbf{N}$ & I students & $2^{2}=58.8$ & & & \\
\hline
\end{tabular}

Table-2 Correlates of overweight and obesity in medical students

\begin{tabular}{|c|c|c|c|}
\hline CORRELATING FACTORS & $\begin{array}{c}\text { BODY MASS INDEX } \\
(\mathbf{N}=\mathbf{8 2}) \\
\left(\square \mathbf{2 5 K g} / \mathbf{M}^{2}\right)\end{array}$ & $\begin{array}{c}\text { WAIST HIP RATIO } \\
(\mathrm{N}=47) \\
\text { ( >1 In Males And } \\
>0.85 \text { In Females) }\end{array}$ & $\begin{array}{c}\text { WAIST } \\
\text { CIRCUMFERENCE } \\
\text { (N=15) } \\
\text { ( } \square 102 \mathrm{~cm} \text { In Males } \\
\text { And } \square 88 \mathrm{~cm} \text { In } \\
\text { Females) }\end{array}$ \\
\hline \multicolumn{4}{|l|}{ DIETARY HABITS } \\
\hline Vegetarian & $74(90.24 \%)$ & $37(78.7 \%)$ & $10(66.67 \%)$ \\
\hline Non Vegetarian & $8(9.76 \%)$ & $10(21.28 \%)$ & $5(33.33 \%)$ \\
\hline \multicolumn{4}{|l|}{ EAT IN BETWEEN MEALS } \\
\hline Never & $5(6.09 \%)$ & $1(2.13 \%)$ & $2(13.33 \%)$ \\
\hline Tea & $13(15.85 \%)$ & $3(6.38 \%)$ & $1(6.67 \%)$ \\
\hline Snacks & $14(17.07 \%)$ & $7(14.89 \%)$ & $1(6.67 \%)$ \\
\hline Fruits & $12(14.63 \%)$ & $6(12.77 \%)$ & $3(0.2 \%)$ \\
\hline Chips And Dairy Products & $3(3.66 \%)$ & $4(8.51 \%)$ & $1(6.67 \%)$ \\
\hline Cold Drinks & $1(1.22 \%)$ & $0(0 \%)$ & $0(0 \%)$ \\
\hline Multiple Responses & $34(41.46 \%)$ & $26(55.32 \%)$ & $7(46.67 \%)$ \\
\hline \multicolumn{4}{|l|}{ DIETARY PREFERENCES } \\
\hline Sweets & $19(23.17 \%)$ & $6(12.77 \%)$ & $2(13.33 \%)$ \\
\hline Chocolates & $13(15.85 \%)$ & $16(34.04 \%)$ & $5(33.33 \%)$ \\
\hline Fatty Foods & $2(2.44 \%)$ & $3(6.38 \%)$ & $0(0 \%)$ \\
\hline Dry Fruits & $11(13.41 \%)$ & $4(8.51 \%)$ & $2(13.33 \%)$ \\
\hline None & $13(15.85 \%)$ & $8(17.02 \%)$ & $2(13.33 \%)$ \\
\hline Multiple Responses & $24(29.27 \%)$ & $10(21.28 \%)$ & $4(26.67 \%)$ \\
\hline \multicolumn{4}{|l|}{ EAT OUTSIDE } \\
\hline Never & $0(0 \%)$ & $0(0 \%)$ & $0(0 \%)$ \\
\hline Daily & $6(7.32 \%)$ & $4(8.51 \%)$ & $2(13.33 \%)$ \\
\hline Weekly & $31(37.80 \%)$ & $15(31.91 \%)$ & $3(0.2 \%)$ \\
\hline Occasionally & $45(54.88 \%)$ & $28(59.57 \%)$ & $10(66.67 \%)$ \\
\hline \multicolumn{4}{|l|}{ TOTAL MEALS } \\
\hline One & $0(0 \%)$ & $0(0 \%)$ & $0(0 \%)$ \\
\hline Two & $33(40.24 \%)$ & $15(31.91 \%)$ & $7(46.67 \%)$ \\
\hline Three & $39(47.56 \%)$ & $28(59.57 \%)$ & $8(53.33 \%)$ \\
\hline More Than Three & $10(12.19 \%)$ & $4(8.51 \%)$ & $0(0 \%)$ \\
\hline
\end{tabular}

According to BMI, the prevalence of overweight and obesity in medical students was $27.4 \%$ and $1.0 \%$ respectively in males as compared to $16.0 \%$ and $0.7 \%$ in females. Similar results have been found in nursing students where the prevalence in males was $19.2 \%$ and $2.6 \%$ while in females it was $14.6 \%$ and $1.9 \%$ respectively. It was observed that the prevalence of underweight is higher in females of both medical and nursing streams. Similar findings were observed in an ICMR funded study conducted by Pradeepa $\mathbf{R}$ et al in which they found that overweight and obesity was $22.2 \%$ in women and $20.9 \%$ in men in rural areas of some states of India [4]. On the other hand, NFHS-3 reported that in India obesity was more prevalent in urban areas compared to rural areas especially in men (urban-15.9\%, rural-5.6\%); women(urban-23.5\%, rural-7.2\%)[5].The higher values reported in ICMR study were probably because they had taken BMI $>23.0 \mathrm{Kg} / \mathrm{m}^{2}$ as cutoff for overweight and obesity. Siddhu et al have observed that $16.8 \%$ of the rural adult have BMI $>25.0\left(\mathrm{~kg} / \mathrm{m}^{2}\right)[6]$. Marie NG et al during their worldwide analysis of published surveys, reports and published article observed that the proportion of adults with a body-mass index (BMI) of $25 \mathrm{~kg} / \mathrm{m}^{2}$ or greater increased between 1980 and 2013 from $28.8 \%(95 \%$ UI $28 \cdot 4-29 \cdot 3)$ to $36 \cdot 9 \%(36 \cdot 3-37.4)$ in men, and from $29 \cdot 8 \%(29 \cdot 3-30 \cdot 2)$ to $38 \cdot 0 \%$ (37.5-38.5) in women. . The prevalence of overweight and obesity has also increased in children and adolescents in developing countries, from $8.1 \%(7 \cdot 7-8.6)$ to $12.9 \%(12 \cdot 3-13 \cdot 5)$ in 2013 for boys and from $8 \cdot 4 \%(8 \cdot 1-8 \cdot 8)$ to $13 \cdot 4 \%(13 \cdot 0-13 \cdot 9)$ in girls. In adults, estimated prevalence of obesity exceeded [7]. Premlal K S et al in their study among the 606 college going adolescents in Kancheepuram observed that 201 (33.4\%) 
were overweight and obese by Indian guidelines, whereas by the WHO guidelines $130(21.5 \%)$ were overweight and obese [8].

As far as waist circumference is concerned, it was observed that $8.76 \%$ females have higher values depicting abdominal fat deposition and it is more than their male (1.49\%) counterparts. It was also observed that the overall fat deposition is higher in medical students $(4.4 \%)$ as compared to nursing students $(0.55 \%)$. In ICMR study by Pradeepa $\mathbf{R}$ et al they have reported that $19.5 \%$ of the rural adults have higher waist circumference [4].

WHR has also been observed to be higher in females of medical and nursing streams as compared to males. In total, the medical students have higher percentage of WHR (13.9\%) as compared to nursing students (9.94\%). Sohani A et al in their study for screening of obesity in adolescents have observed that $42.06 \%$ of the overweight and obese students have higher WHR [9]. The higher prevalence reported by them could be because they considered $\geq 0.9$ as cutoff for WHR.

Dietary correlates of overweight and obesity were higher for vegetarian. It was also observed that majority of the overweight and obese medicos consumed tea, snacks and other products in between meals. Majority had preference for sweets and chocolates. Eating outside, total number of meals was not associated with higher value of overweight and obesity as majority of them were eating outside occasionally and weekly while only few of them consumed more than four meals. Premlal K S et al observed that $23(3.8 \%)$ of total population had habit of consuming fast food daily and 120(19.8\%) had habit of having fast food 3-5 times a week. Similar observations were seen in the dietary habits of nursing students too [8].

\section{Conclusion}

Prevalence of overweight and obesity was higher in medical students. Appropriate health education regarding dietary habits and behavior change communication shall be imparted to the medical students. It is recommended to have elaborative study to find out various factors responsible for high prevalence of overweight and obesity.

[1]. WHO: Obesity and overweight. Available from

\section{References}

[2]. www.who.int/entity/mediacentre/factsheets/fs311/en/-44k. Accessed on 3 December, 2016

[3]. WHO: Obesity, Preventing and managing the Global Epidemic, Tech Rpt Ser, 894, 2000, 102 -104. Available from www.who.int/nutrition/publications/obesity/WHO_TRS_894/en/ Accessed on 03/12/16.

[4]. WHO (2003) Tech Rep Ser No. 916. Available from www.who.int/dietphysical activity/ publication/trs916/en. Accessed on $03 / 12 / 2016$

[5]. R. Pradeepa, R.M. Anjana, Shashank, R. Joshi, A. Bhansali, M. Deepa, Prashant, P. Joshi et al, Prevalence of generalized \& abdominal obesity in urban \& rural India, Indian J Med Res 142, 2015, August, 139-150.

[6]. Ministry of Health and Family Welfare, Govt. of India (2007). National Family Health Survey -3 (NFHS-3) 2005-2006. India. Available from www.rchiips.org/nfhs/NFHS/-3/data/VOL-1/India_volume_I_corrected_17oct08.pdf. Accessed on 03/12/16.

[7]. S. Sidhu, K. Kumari, Incidence of overweight and obesity among urban and rural males of Amritsar, Journal of Exercise Science and Physiotherapy, 2, 2006, 79-83.

[8]. Marie Ng, T. Fleming, M. Robinson, B. Thomson, N. Graetz et al, Global, regional, and national prevalence of overweight and obesity in children and adults during 1980-2013: a systematic analysis for the Global Burden of Disease Study 2013, Lancet, 384(9945), 2014, Aug 30, 746.

[9]. K. S. Premlal, B. Arumugam, S. Nagalingam, Prevalence of overweight and obesity among college going students at Kancheepuram town, Tamil Nadu, International Journal of Preventive and Public Health Sciences, 1(6), 2016, Mar- Apr,15-19.

[10]. A. Sohani, S. Chincholikar, B. Patnaik, S. Raje, Indian Journal of Community Health, 27(03), 2015, Jul-Sep, 304-310. 